\title{
CHARACTERIZATION OF THE HEMICELLULOSIC FRACTION OBTAINED AFTER PRE-HYDROLYSIS OF PINUS RADIATA WOOD CHIPS WITH HOT-WATER AT DIFFERENT INITIAL PH
}

\author{
PABLO REYES, ${ }^{a, b}$ REGIS TEIXEIRA MENDONÇA, ${ }^{a, b, *}$ JAIME RODRÍGUEZ, ${ }^{a, b}$ \\ PEDRO FARDIM, ${ }^{c}$ BEATRIZ VEGAc \\ ${ }^{a}$ Centro de Biotecnología, Universidad de Concepción, Casilla 160-C, Concepción, Chile. \\ ${ }^{b}$ Facultad de Ciencias Forestales, Universidad de Concepción, Casilla 160-C, Concepción, Chile. \\ ${ }^{c}$ Laboratory of Fibre and Cellulose Technology, Faculty of Technology, Åbo Akademi University, Porthansgatan 3, FI-20500, Ảbo/Turku, Finland.
}

(Received: July 12, 2012 - Accepted: November 14, 2012)

\begin{abstract}
Hemicelluloses from Pinus radiata wood chips were extracted using different conditions of temperature, time and initial $\mathrm{pH}$ of water $\left(120\right.$ to $170^{\circ} \mathrm{C}, 30$ to 120 min and $\mathrm{pH} 2$ to 12 , respectively). Results showed that hemicelluloses represented $26 \%$ of wood dry weight and, from this amount, hexoses are responsible for $64 \%$ of its composition. The analysis of extraction results showed that $\mathrm{pH}$ has a low effect in disassembling hemicelluloses from wood, and that time and temperature of reaction were the most important parameters. Maximal amount of hemicellulose extracted in the most severe conditions tested was between $12-16 \%$ (on wood basis). In these conditions approximately $40-50 \%$ of the hemicellulose in wood was solubilized. As observed by SEC analysis, the recovered hemicellulosic fractions were in the form of low molar mass oligomers with Mw varying from 3720 to $54300 \mathrm{~g} / \mathrm{mol}$. The FT-IR spectra show peak multiplicity between 1120 and $1000 \mathrm{~cm}^{-1}$ that is a typical characteristic of carbohydrates and only alkaline-extracted hemicelluloses showed the presence of lignin with a characteristic peak at $1509 \mathrm{~cm}^{-1}$.
\end{abstract}

Keywords: Pinus radiata, hemicelluloses, galactoglucomannans, biorefinery.

\section{INTRODUCTION}

Hemicelluloses are a fraction of wood polysaccharides that is formed by different anhydrosugars units, arranged in different proportions and with different substituents, where the main monomeric units are $\beta$-Dglucose, $\beta$-D-mannose, $\beta$-D-galactose, $\beta$-D-xylose and $\beta$-L-arabinose. Other monosacharides that occur in small amounts are $\alpha$-L-rhamnose, $\alpha$-L-fucose, $\alpha$-D-galacturonic acid and $\alpha$-D-glucuronic acid'. Hemicelluloses have a lower degree of polymerization (DP) than cellulose (approximately $200 \mathrm{vs}$. over 7000 , respectively) and are linked to lignin via hydrogen and covalent bonds ${ }^{1,2}$. Chemical bonds between lignin and hemicellulose components can be ester or ether type linkages. Ether linkages between lignin and carbohydrates are more common and stable while the ester linkages are easily cleaved by alkali ${ }^{1,3,4}$. There are different types and amount of hemicelluloses in hardwoods (angiosperms) and softwoods (gimnosperms). Hardwoods contained primarily glucuronoxylans, while softwoods contain mainly galactoglucomannans. The amount of these hemicelluloses in the wood varied roughly from 20 to $35 \%{ }^{1}$.

In the chemical processing of wood most of the hemicellulosic fraction is solubilized during the cooking process used to produce cellulose for the pulp and paper industry. The residual black liquor contained also the lignin and both components are burned in the recovery boiler for energy and inorganics recovery ${ }^{5-7}$. However, this polysaccharide fraction could be a potential source for biofuels and bio-based chemicals in the biorefinery concept ${ }^{8-10}$. In order to utilize hemicelluloses from biomass as a feedstock for production of high-value added products it is essential to assess its chemical composition, molar weight and other characteristics that could be useful for its use in a given process or for an specific product.

In recent years, extraction of hemicelluloses from wood has attained a growing interest ${ }^{11-13}$. The chemical alterations and its solubility depend on the composition of the extraction liquor, temperature and reaction time. The reactions that occur during the removal of hemicellulose involve hydrolysis of the covalent bonds that link the hemicelluloses with lignin.

Yoon et al..$^{13}$ performed the extraction of hemicelluloses from Pinus taeda (a softwood) with pressurized hot water, reporting a significant weight loss of wood and generation of an oligomeric fraction of carbohydrates, which was directly related to the increase of time and temperature of extraction. Extracts composition showed that oligomeric arabinans and xylans were removed at the beginning of the hydrolysis process, and were found in monomeric form (as arabinose and xylose) at longer extraction times. Glucomannans remained mostly in oligomeric form even at high severity extraction conditions. Most of the monomeric glucose in the extract originates from the glucomannan fraction. Paredes et al. ${ }^{14}$ and van Heiningen et al. ${ }^{15}$ showed that up to $80 \%$ of the acetyl-galactoglucomannans can be extracted from ground softwood by heat treatment with water at high temperatures $\left(190-200^{\circ} \mathrm{C}\right)$ for a few minutes (2-5), although the degree of polymerization was significantly lower than the obtained in extractions with wood chips (DP of $24 v s .150$, respectively).

Song et al. ${ }^{16}$ studied the extraction of galactoglucomannan (GGM) from spruce wood with pressurized hot water. Results showed that the amount of galactose, glucose and mannose units determined in extracts accounted for approximately $75 \%$ of the total carbohydrates, indicating a preferable extraction of galactoglucomannan. Higher temperatures and longer extraction times led to a lower $\mathrm{pH}$ level, causing deacetylation of GGM, and consequently, the solubility of GGM in the liquor and a decrease in its yield. Tunc and van Heiningen $^{3}$ studied the composition of hemicellulosic hydrolysates from a mixture of southern hardwoods obtained by autohydrolysis process. Authors reported that the yield of oligomeric carbohydrates increased continuously with the increase of extraction temperature (from 160 to $170^{\circ} \mathrm{C}$ ). It was also observed a low degree of polymerization (DP) of oligomers in the extracts. With the increase of temperature, there was also an increase in the yield of carbohydrates extracted but the degree of polymerization decreases due to the hydrolysis of the oligomers at the more severe conditions. Ban et al. ${ }^{17}$ studied the isolation of oligosaccharides from birch (a hardwood) employing varied $\mathrm{pH}$ aqueous solutions. Results showed that acidic conditions provided a higher extraction yield versus alkaline conditions. In alkaline conditions there was also a higher extraction of lignin that contaminated the carbohydrate fraction, especially at high temperature conditions.

Considering that Pinus radiata is the main commercial softwood species used by the Chilean pulp and paper industry, and that its hemicellulosic fraction could be a potential source of raw material for biofuels or bioproducts, the aim of this work was to disassemble the hemicelluloses from P. radiata wood chips using hot-water with $\mathrm{pH}$ adjusted to acid, neutral and alkaline followed by the characterization of the extracts using different analytical techniques. Depending on the characteristics of the extracts obtained, possible uses were proposed according to a biorefinery concept.

\section{EXPERIMENTAL}

\section{Extraction of hemicelluloses}

Pinus radiata wood chips were provided by a pulp mill from the BioBio Province, Chile. Hemicellulose extraction was carried out under different aqueous solutions composition, time and temperature, in order to evaluate different profiles and yields of carbohydrates removal. The variables studied were the initial $\mathrm{pH}$ of the water solution $(2,7$ and 12$)$, temperature $\left(120^{\circ} \mathrm{C}\right.$ to 
$170^{\circ} \mathrm{C}$ ) and reaction time at maximum temperature (30 to $\left.120 \mathrm{~min}\right)$. The assays were performed according to a Box-Behnken experimental design (Table 1). The variable values were coded and normalized in unitary values, -1 is defined as the lowest value of a variable and +1 is defined as its highest value. From these extreme variable values, the central point (coded 0 ) was set and assayed in triplicate. Each reaction was carried out in a 1.2-L high-pressure digester with recirculation liquor (HAATO, Vantaa, Finland) using a temperature ramp of $5^{\circ} \mathrm{C} / \mathrm{min}$. The extraction conditions were applied to $200 \mathrm{~g} \mathrm{P}$. radiata wood chips (dry basis) using $1000 \mathrm{~mL}$ of liquor prepared with deionized water and with the $\mathrm{pH}$ adjusted with $\mathrm{HCl}$ or $\mathrm{NaOH}$ solutions. After each reaction, the residue was cooled to room temperature, filtered and washed with $100 \mathrm{~mL}$ of water. Solids were air-dried, the exact moisture determined and the residual wood chips were weighed. The volume of the liquid fraction recovered was reduced to approximately $100 \mathrm{~mL}$ in a rotatory evaporator (Buchi, Switzerland) and $400 \mathrm{~mL}$ of $95 \%$ ethanol was added to the aqueous fraction to precipitate the oligosaccharides. The precipitated was filtered in a $0.25 \mu \mathrm{m}$ membrane filter, washed with ethanol and dried in a vacuum oven at $40^{\circ} \mathrm{C}$. Solids were weighed to determine the yield of hemicellulose extracted and for further chemical analysis.

Table 1. Experimental design used for hemicelluloses extraction from $P$. radiata wood chips.*

\begin{tabular}{|c|c|c|c|}
\hline Experiment & Time $(\mathrm{min})$ & Temperature $\left({ }^{\circ} \mathrm{C}\right)$ & Initial $\mathrm{pH}$ \\
\hline 1 & $30(-1)$ & $120(-1)$ & $7(0)$ \\
\hline 2 & $120(1)$ & $120(1)$ & $7(0)$ \\
\hline 3 & $30(1)$ & $170(-1)$ & $7(0)$ \\
\hline 4 & $120(1)$ & $170(1)$ & $7(0)$ \\
\hline 5 & $30(-1)$ & $145(0)$ & $2(-1)$ \\
\hline 6 & $120(1)$ & $145(0)$ & $2(-1)$ \\
\hline 7 & $30(-1)$ & $145(0)$ & $12(1)$ \\
\hline 8 & $120(1)$ & $145(0)$ & $12(1)$ \\
\hline 9 & $75(0)$ & $120(-1)$ & $2(-1)$ \\
\hline 10 & $75(0)$ & $170(1)$ & $2(-1)$ \\
\hline 11 & $75(0)$ & $120(-1)$ & $12(1)$ \\
\hline 12 & $75(0)$ & $170(1)$ & $12(1)$ \\
\hline 13 & $75(0)$ & $145(0)$ & $7(0)$ \\
\hline 14 & $75(0)$ & $145(0)$ & $7(0)$ \\
\hline 15 & $75(0)$ & $145(0)$ & $7(0)$ \\
\hline
\end{tabular}

* The coded values for the variables are in parentheses.

\section{Chemical composition of wood and hemicellulosic extracts}

Wood chips were milled in a knife mill, and sieved to $45 / 60$ mesh. Milled wood was extracted with acetone $90 \%$ for $16 \mathrm{~h}$ to determine the amount of extractives. Hemicellulose-extracted wood chips were also milled and sieved but not extracted with acetone. Milled wood samples were hydrolyzed with $72 \%$ sulfuric acid at $30^{\circ} \mathrm{C}$ for $1 \mathrm{~h}$ ( $300 \mathrm{mg}$ of sample and $3 \mathrm{~mL}$ of sulfuric acid). The acid was diluted to $4 \%$ (by the addition of $84 \mathrm{~mL}$ of water) and the mixture heated at $125^{\circ} \mathrm{C} / 1 \mathrm{~atm}$ for $1 \mathrm{~h}$. The residual material was cooled and filtered through porous glass filter number 4 . Solids were dried to constant weight at $105^{\circ} \mathrm{C}$ and determined as insoluble lignin. The soluble lignin concentration in the filtrate was determined by the measurement of the absorbance at $205 \mathrm{~nm}$ and using the value of $110 \mathrm{~L} / \mathrm{g} . \mathrm{cm}$ as the absorptivity of soluble lignin. The concentration of monomeric sugars (mainly cellobiose, glucose and mannose) in the soluble fraction were determined by HPLC (Merck Hitachi, Germany) using a BIORAD HPX- $87 \mathrm{H}$ column at $45^{\circ} \mathrm{C}$, eluted at the $0.6 \mathrm{~mL} / \mathrm{min}$ with $0.005 \mathrm{~mol} / \mathrm{L}$ sulfuric acid. Sugars were detected in a $30^{\circ} \mathrm{C}$-temperature controlled RI detector ${ }^{18}$.

The detailed composition of monosaccharides in the hemicellulosic fraction was determined by acid methanolysis-gas chromatography according to Sundberg et al. ${ }^{19}$. In a pear-shaped flask, it was weighted $10 \mathrm{mg}$ milled wood or $3 \mathrm{mg}$ hemicellulose (recovered from the ethanolic solution) and were added $2 \mathrm{~mL}$ of $2 \mathrm{M} \mathrm{HCl}$ solution in anhydrous methanol. The samples were kept in an oven at $100^{\circ} \mathrm{C}$ for $3 \mathrm{~h}$. After cooling to room temperature, $100 \mu \mathrm{L}$ pyridine was added to neutralize the acidic solution. Additionally, $4 \mathrm{~mL}$ methanol solution was added containing sorbitol as internal standard $(0.1 \mathrm{mg} / \mathrm{mL})$. One
$\mathrm{mL}$ of fiber-free solution was transferred into another pear-shaped flask. The solution was evaporated in a rotary evaporator with a water bath kept at $40^{\circ} \mathrm{C}$. To ensure complete removal of the methanol, the sample was further dried in a vacuum desiccator for $20 \mathrm{~min}$ at $40^{\circ} \mathrm{C}$. The sample was dissolved by addition of $100 \mu \mathrm{L}$ pyridine. For silylation, $150 \mu \mathrm{L}$ HMDS (hexamethyldisilazane, Fluka) and $80 \mu \mathrm{L}$ TMCS (trimethylchlorosilane, Merck) were added and the samples were shaken and maintained for $4 \mathrm{~h}$ at room temperature. The sample was injected in split mode (split ratio $1: 20$ at $260^{\circ} \mathrm{C}$ ) in a DB-5 column $(95 \%$ dimethyl polisiloxane, $5 \%$ diphenyl, Agilent Technologies) with $30 \mathrm{~m} \times 0.25$ $\mathrm{mm}$ id $\mathrm{x} 0.25 \mu \mathrm{m}$ film thickness. The initial column temperature was $100^{\circ} \mathrm{C}$ increased at $4{ }^{\circ} \mathrm{C} / \mathrm{min}$ to $175^{\circ} \mathrm{C}$, then $175^{\circ} \mathrm{C}$ increased at $12^{\circ} \mathrm{C} / \mathrm{min}$ to $290^{\circ} \mathrm{C}$. FID detector temperature was $290^{\circ} \mathrm{C}$ and nitrogen was used as carrier gas. The quantification of sugars was done through calibration curves constructed with chromatographic grade standards of the following compounds arabinose, rhamnose, xylose, mannose, galactose, glucose and glucuronic acid, and considering the response factors in relation to the internal standard (sorbitol).

\section{Molar weight distribution of hemicelluloses}

Weight-average molar weight $\left(\mathrm{M}_{w}\right)$ and number-average molar weight $\left(M_{n}\right)$ of the hemicelluloses were determined by size exclusion chromatography in $\mathrm{DMSO} / \mathrm{LiBr}$ in a system from Jasco with SEC-pump PU-980; RI detector (RI- 930); NOVEMA 3000 and NOVEMA 300 columns; $0.5 \mathrm{~mL} / \mathrm{min}$ flow rate; $65^{\circ} \mathrm{C}$ temperature. The calculations were done with the software WinGPC (Polymerstandardservice, PSS Mainz, Germany) with pullulans as standard to determine $\mathrm{M}_{\mathrm{w}}$ and $\mathrm{M}_{\mathrm{n}}$ of hemicelluloses.

\section{FT-IR of hemicelluloses}

FT-IR measurements were performed in order to analyze the chemical groups present in hemicelluloses and also the possible changes caused by the extraction process. FT-IR spectra were recorded on a Bruker, IFS 66S spectrometer using deuterated triglycine sulfate (DTGS) detector. About 2.0 $\mathrm{mg}$ of each dried sample were grained together with $\mathrm{KBr}(200 \mathrm{mg}$, Merck spectroscopic grade, dried before use) and pressed with hydraulic press (8-10 tons) into $13 \mathrm{~mm}$ pellets. Spectra were recorded using normal transmission technique (from 5000 to $500 \mathrm{~cm}^{-1}$ ) at transmittance mode, running 64 scans for each spectrum.

\section{RESULTS AND DISCUSSION}

Yield and chemical composition of hemicellulosic extracts

Chemical characterization of $P$. radiata wood chips showed that hemicelluloses represented approximately $27 \%$ of wood dry weight and, from this amount; hexoses (glucose, mannose and galactose) are responsible for $64 \%$ of its composition while pentoses (arabinose and xylose) represented $24 \%$ (Figure 1). Small amounts of a deoxysugar (rhamnose), glucuronic acids and other carbohydrates (pectins and gums, for instance) are also present and are reported as other components. The carbohydrates detected are part of the two main hemicelluloses structures found in softwood species, the galactoglucomannans and the arabinoglucuronoxylans ${ }^{1}$.

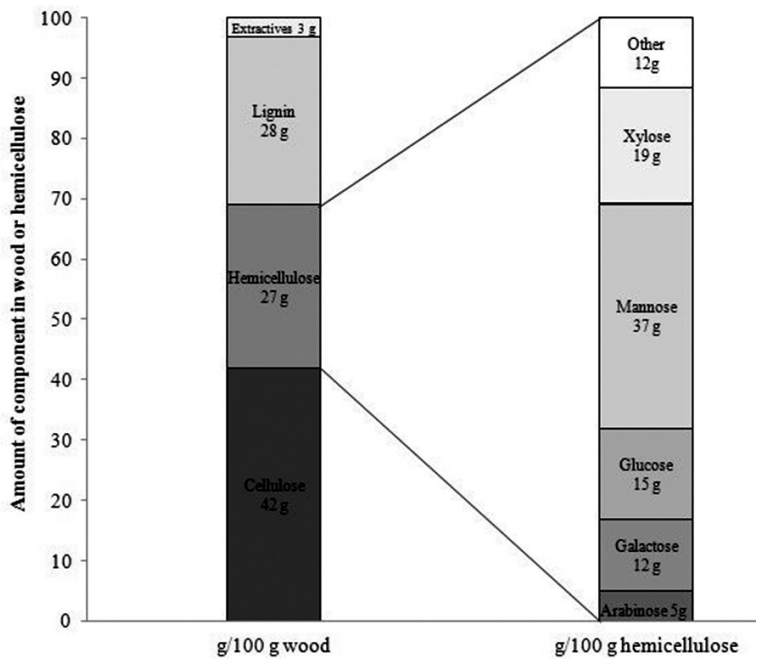

Figure 1. Chemical composition of wood and hemicelluloses of Pinus radiata. 
Different extraction conditions with water at high temperature and different initial $\mathrm{pH}(2,7$ and 12) where applied in order to obtain different extraction yields and composition. The amount of ethanol-precipitated hemicellulose recovered from the aqueous extracts varied from $2 \mathrm{~g}$ to $15 \mathrm{~g} / 100$ $\mathrm{g}$ wood (from 7 to $58 \%$ of the hemicellulose amount in wood), with mannose being the component extracted with the highest amount in all conditions. Table 2 summarizes the results obtained for the yield of oligosaccharides recovered in the extracts, as well as, its composition for different sugars classified according to the different initial $\mathrm{pH}$ of the aqueous solution.

Table 2: Range of yield and of amount of components in the hemicellulosic extracts of $P$. radiata obtained by extraction with hot-water at different initial $\mathrm{pH}$.

\begin{tabular}{|c|c|c|c|}
\hline & $\begin{array}{c}\text { Extractions at } \\
\text { pH 2 }\end{array}$ & $\begin{array}{c}\text { Extractions at } \\
\text { pH 7 }\end{array}$ & $\begin{array}{c}\text { Extractions at } \\
\text { pH 12 }\end{array}$ \\
\hline Hemicellulose yield $^{\mathrm{a}}$ & $3.8-13.3$ & $2.2-15.2$ & $3.9-10.2$ \\
\hline Arabinose $^{\mathrm{b}}$ & $1.7-8.1$ & $1.1-6.8$ & $1.8-3.3$ \\
\hline Galactose $^{\mathrm{b}}$ & $16.8-20.7$ & $9.9-21.4$ & $14.1-17$ \\
\hline Glucose $^{\mathrm{b}}$ & $11.5-15.4$ & $7.6-23.2$ & $10.3-14.5$ \\
\hline Mannose $^{\mathrm{b}}$ & $36.0-43.0$ & $26.2-51.1$ & $26.7-48.9$ \\
\hline Rhamnose $^{\mathrm{b}}$ & $0.3-1.3$ & $0.2-2.8$ & $0.3-2.3$ \\
\hline Xylose & $5.3-12.5$ & $5.1-18.7$ & $5.0-23.1$ \\
\hline $\begin{array}{c}\text { Lignin and other } \\
\text { compounds }\end{array}$ & $9.5-17.4$ & $1.0-31.8$ & $4.0-34.2$ \\
\hline
\end{tabular}

${ }^{\mathrm{a}} \mathrm{g}$ hemicellulose/100 $\mathrm{g}$ wood; ${ }^{\mathrm{b}} \mathrm{g}$ component/100 $\mathrm{g}$ hemicellulose.

The results obtained were used to develop the different models based on Box-Behnken regression and allowed the determination of quadratic polynomials for the yield of the hemicelluloses recovered, the amount of hexoses and pentoses in the hemicellulosic fraction (Equations 1, 2 y 3, respectively).

$\mathbf{Y}_{1}=1.34+0.39 \mathrm{X}_{1}+0.80 \mathrm{X}_{2}-0.12 \mathrm{X}_{3}+0.24 \mathrm{X}_{1}^{2}+0.36 \mathrm{X}_{2}^{2}$

$\mathbf{Y}_{2}=0.45+0.43 \mathrm{X}_{1}+0.73 \mathrm{X}_{2}-0.12 \mathrm{X}_{3}+0.31 \mathrm{X}_{1}^{2}+0.42 \mathrm{X}_{2}^{2}+0.20 \mathrm{X}_{3}^{2} \quad$ (Eq. 2)

$\mathbf{Y}_{3}^{2}=0.85+0.43 \mathrm{X}_{1}+0.71 \mathrm{X}_{2}+0.20 \mathrm{X}_{3}+0.46 \mathrm{X}_{1}^{2} \quad$ (Eq. 3)

Where $\mathbf{Y}_{1}$ is the amount of ethanol-precipitated hemicellulose recovered from the extracts ( $\mathrm{g} / 100 \mathrm{~g}$ wood), $\mathbf{Y}_{2}$ is the content of hexoses in the recovered hemicellulose fraction $\left(\mathrm{g} / 100 \mathrm{~g}\right.$ wood), $\mathbf{Y}_{3}$ is the content of pentoses in the recovered hemicellulose fraction $\left(\mathrm{g} / 100 \mathrm{~g}\right.$ wood), $\mathbf{X}_{1}$ is the cooking time (min), $\mathbf{X}_{2}$ is the temperature $\left({ }^{\circ} \mathrm{C}\right)$ and $\mathbf{X}_{3}$ is the initial $\mathrm{pH}$ of the aqueous solution. The values of the ANOVA test that gave statistical validity to the model for equation 1 were: $\mathrm{R}^{2}=0.99, \mathrm{Q}^{2}=0.79$, model validation 0.66 and reproducibility of the model 0.99; for equation 2 were: $\mathrm{R}^{2}=0.98, \mathrm{Q}^{2}=0.80$, model validation 0.53 and reproducibility of the model 0.99 and for equation 3 were: $\mathrm{R}^{2}=0.88, \mathrm{Q}^{2}=0.56$, model validation 0.72 and reproducibility of the model 0.85 . The error values corresponded to a $95 \%$ confidence level. In equations 1 and 2 , the linear terms for time and temperature have positive coefficients, meaning that the content of hemicellulose or hexoses increased with the increase of these variables unti a maximum value. Statistical analysis showed that the $\mathrm{pH}$ of solution was not a variable that influenced directly in the process according to the statistical model, similar to that describe by Franco et al. ${ }^{20}$. Temperature was the main determining factor for maximum extraction of hemicelluloses, continued to time of extraction. In equation 3 , the linear terms for time, temperature and $\mathrm{pH}$ have positive coefficients, meaning that the content of pentoses increased with the increased these variables until a maximum value.

Regarding the monomeric sugars present in the recovered fraction it was possible to model the amount of mannose, galactose and glucose in the extracts (equations 4, 5 and 6, respectively).

$$
\begin{gathered}
\mathbf{Y}_{4}=0.49+0.40 \mathrm{X}_{1}+0.74 \mathrm{X}_{2}-0.13 \mathrm{X}_{3}+0.27 \mathrm{X}_{1}{ }^{2}+0.40 \mathrm{X}_{2}{ }^{2} \\
\quad(\text { Eq. 4) } \\
\mathbf{Y}_{5}=0.39+0.45 \mathrm{X}_{1}+0.63 \mathrm{X}_{2}-0.14 \mathrm{X}_{3}+0.36 \mathrm{X}_{1}{ }^{2}+0.49 \mathrm{X}_{2}{ }^{2}+0.37 \mathrm{X}_{3}{ }^{2} \\
\quad \text { Eq. 5) } \\
\mathbf{Y}_{6}=0.39+0.41 \mathrm{X}_{1}+0.69 \mathrm{X}_{2}-0.18 \mathrm{X}_{3}+0.27 \mathrm{X}_{1}{ }^{2}+0.49 \mathrm{X}_{2}{ }^{2}+0.22 \mathrm{X}_{3}{ }^{2} \\
\quad \text { Eq. 6) }
\end{gathered}
$$

Where $\mathbf{Y}_{4}$ is the content of mannose, $\mathbf{Y}_{5}$ is the amount galactose and $\mathbf{Y}_{6}$ is the amount glucose in the recovered hemicelluloses fraction $(\mathrm{g} / 100 \mathrm{~g}$ wood). The values of the ANOVA test that gave statistical validity to the model for equation 4 were: $\mathrm{R}^{2}=0.93, \mathrm{Q}^{2}=0.66$, model validation 0.26 and reproducibility of the model 0.98; for equation 5 were: $\mathrm{R}^{2}=0.98, \mathrm{Q}^{2}=0.76$, model validation 0.64 and reproducibility of the model 0.98 and for equation 6 were: $\mathrm{R}^{2}=0.97$, $\mathrm{Q}^{2}=0.79$, model validation 0.32 and reproducibility of the model 0.99 . The error values corresponded to a $95 \%$ confidence level.

An example of the contour surfaces obtained for the modeling of the results of the experimental design is shown in Figure 2 for the yield of hemicellulose recovered after precipitation with ethanol. Ban et al. ${ }^{17}$ extracting hemicellulose from birch wood, indicated that the temperature is the most important factor for extraction and is independent of the initial $\mathrm{pH}$ of the liquor, this is similar to the findings of our research, where there is little effect of the initial $\mathrm{pH}$ and the temperature has a major effect in the yield of extraction.
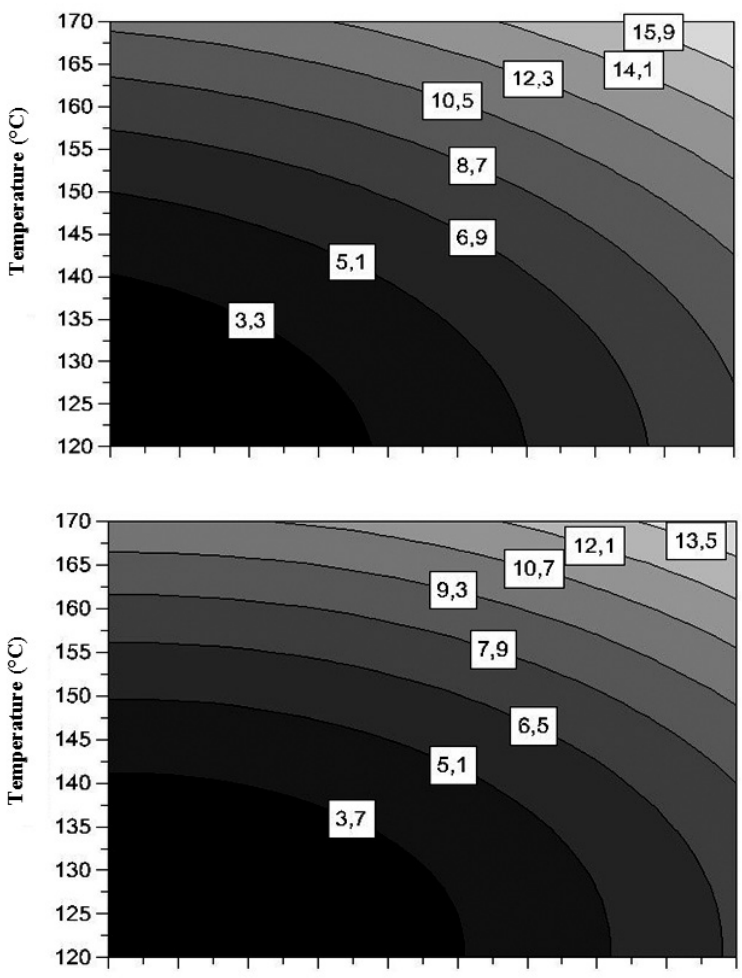

(B)

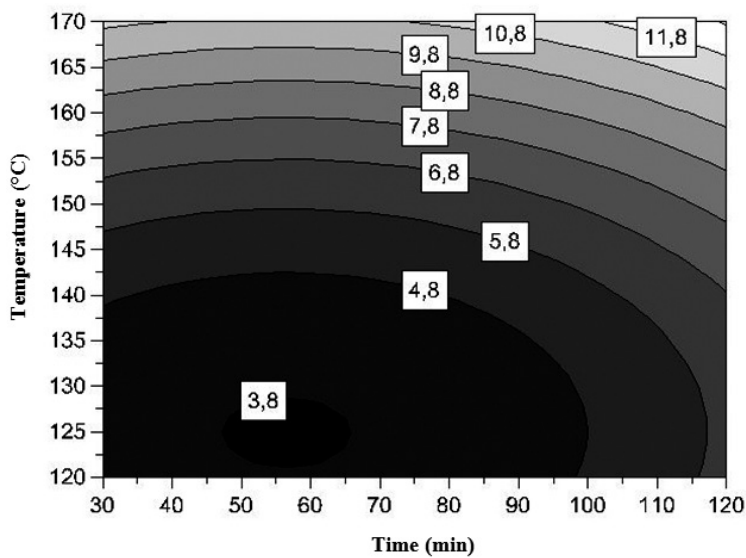

(C)

Figure 2. Contour surface for the yield of hemicelluloses recovered from the (a) acid; (b) neutral and (c) alkaline aqueous solutions.

\section{Molar mass distribution}

The molar mass distribution of the hemicellulosic fraction recovered from 
the extracts was also determined and presented a highly variable values that were dependent of the severity of the extraction and covered from $\mathrm{Mw}=3720$ $\mathrm{g} / \mathrm{mol}$ to $\mathrm{Mw}=54300 \mathrm{~g} / \mathrm{mol}$ (Figure 3). Low Mw was found in most of the samples, especially in acidic and neutral extractions product of conditions applied which also favored the hydrolysis of the oligomers during extraction procedure. In neutral extraction, at elevated temperature and short extraction time $\left(170^{\circ} \mathrm{C}, 30 \mathrm{~min}\right)$, polysaccharides with higher average apparent molar mass $(17000 \mathrm{~g} / \mathrm{mol})$ were extracted. Prolonged time of extraction at high temperature $\left(170^{\circ} \mathrm{C}, 120 \mathrm{~min}\right)$ yielded polysaccharides with lower average apparent molar mass $(3720 \mathrm{~g} / \mathrm{mol})$, similar effect in the molar mass distribution were also observed by Lundqvist et al. ${ }^{21}$.

The polydispersity $(\mathrm{Mw} / \mathrm{Mn})$ in the hemicelluloses of most of the extracts were high, presenting wide distribution in the molecular weight, product of different severity of the extraction process. In acid extraction, at low temperature and short time $\left(145^{\circ} \mathrm{C}, 30 \mathrm{~min}\right)$ the value was 9.5 and, with increasing time and temperature $\left(170^{\circ} \mathrm{C}, 75 \mathrm{~min}\right)$, the value was 3.6. Neutral extraction of the hemicelluloses obtained showed differing molar masses. Low temperature and short time $\left(120^{\circ} \mathrm{C}, 30 \mathrm{~min}\right)$ had polydispersity values of 36.5 , the maximum value found in all conditions tested. Increasing the time and temperature to $\left(170^{\circ} \mathrm{C}\right.$ and $120 \mathrm{~min}$ resulted in a polydispersity of 2.4. Alkaline condition showed similar trend as acid and neutral conditions, high polydispersity index (25.7) when extraction conditions were less severe $\left(145^{\circ} \mathrm{C}, 30 \mathrm{~min}\right)$ and low polydispersity $(3.0)$ indices when the temperature and time extraction increased $\left(170^{\circ} \mathrm{C}, 75 \mathrm{~min}\right)$.
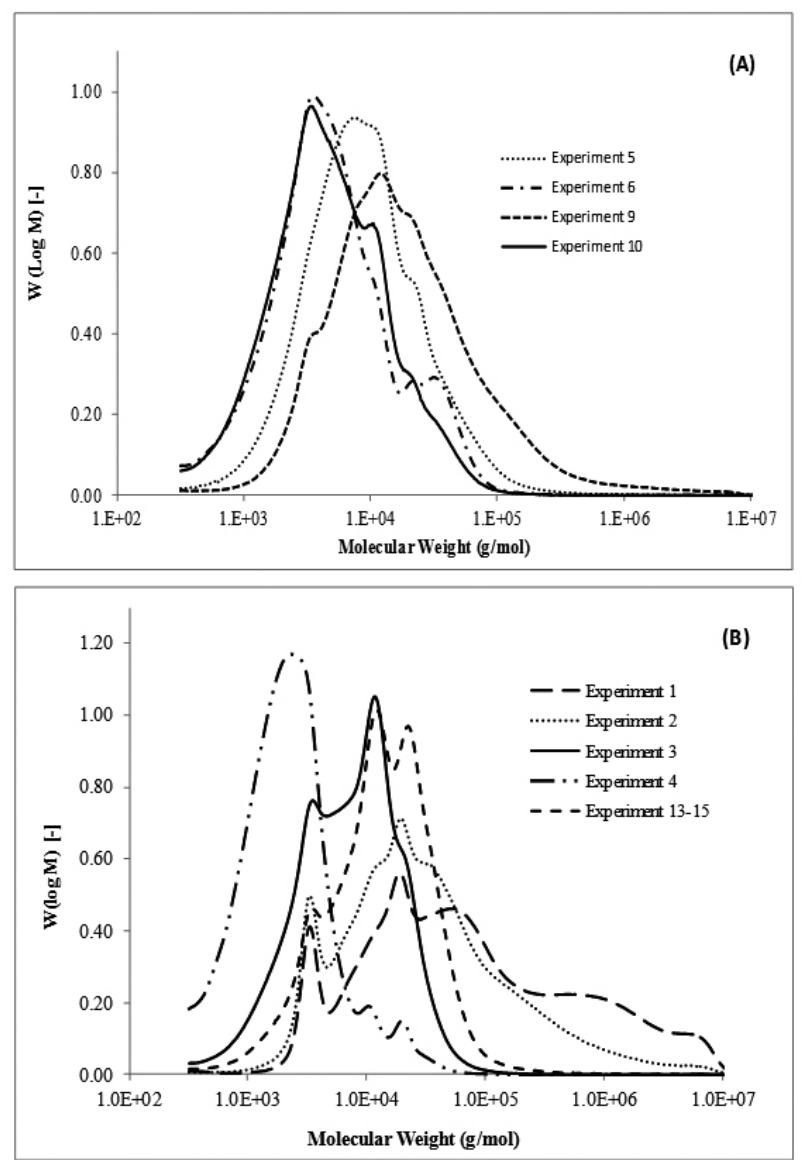

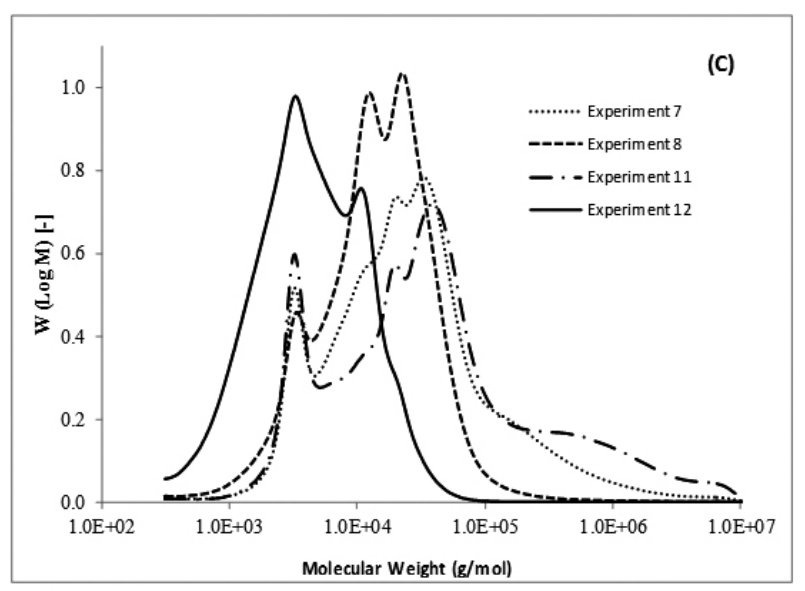

Figure 3. Size-exclusion chromatograms of hemicelluloses obtained from (a) acidic, (b) neutral and (c) alkaline extractions.

\section{FT-IR Analysis}

The FT-IR spectra of hemicelluloses obtained by extraction in neutral conditions (Experiments 1 to 4 ) are shown in Figure 4a. The peak multiplicity between 1120 and $1000 \mathrm{~cm}^{-1}$ is a typical characteristic of carbohydrates. The signal at 1051 and $1008 \mathrm{~cm}^{-1}$ corresponding to the glycosidic $(\mathrm{C}-\mathrm{O}-\mathrm{C})$ stretching cannot be clearly distinguished due to the multiplicity of the peaks in that region. Signals at 1453,1426 , and $1338 \mathrm{~cm}^{-1}$ are attributed to $-\mathrm{CH}_{2}$ symmetric bending, $\mathrm{CH}$ and $\mathrm{OH}$ bending, and $-\mathrm{CH}$ wagging, respectively 22. A small sharp band at $903 \mathrm{~cm}^{-1}$ is indicative of typical for $\beta$-anomers that indicated the presence of dominant $\beta$-glycosidic linkages between the sugar units in all the hemicellulosic fractions. The signal at $1639 \mathrm{~cm}^{-1}$ is due to the absorbed water, but it can also reveal the presence of conjugated carbonyl groups that are either present in the polyphenolic structure of lignin or result from carbohydrate oxidation. The characteristics peaks for lignin are not observed in the FT-IR spectra and indicated low content of lignin in the precipitated. A C-O stretching vibrations of acetyl, uronic, and ferulic ester groups at $1726 \mathrm{~cm}^{-1}$ was not distinguished. The characteristic peak at $1509 \mathrm{~cm}^{-1}$ which indicates the aromatic skeletal vibration of lignin and correspondingly, the band at $1267 \mathrm{~cm}^{-1}$ associated with guaiacyl nuclei and the band at $1233 \mathrm{~cm}^{-1}$ related to syringyl nuclei of plane at position 2, 5, and 6 in $\mathrm{G}$ units could not be distinguished. The peak at $822 \mathrm{~cm}^{-1}$ was attributed to $\mathrm{C}-\mathrm{H}$ out of plane at positions 2 and 6 of $\mathrm{S}$ units and all positions of $\mathrm{H}$ units was not detected ${ }^{23}$. The FT-IR spectra of hemicellulose obtained under acidic conditions were similar to the neutral extractions, having peaks and bands similar (results not showed). The FT-IR spectra of hemicelluloses obtained under alkaline conditions are shown in Figure 4b. The characteristic peak at $1509 \mathrm{~cm}^{-1}$ which indicates the aromatic skeletal vibration of lignin was clear at $\mathrm{pH} 12$ at all temperatures and all extraction times, but is not clearly seen at $\mathrm{pH} 2$ or $\mathrm{pH} 7$. At the same temperature, this signal is stronger when the time is increased.

A biorefinery is a facility that integrates biomass conversion processes and equipment to produce fuels, power, and chemicals from biomass ${ }^{8,24}$. Under this concept hemicellulose play an important role in the integration and economical support of the biorefinery together with other main and co-products. According to its composition and structure, hemicelluloses are suitable for production of liquid biofuels such as bioethanol and bio-products with high added value such as chemicals, polymers, adhesives, pharmaceuticals and dietary fibers, among other $^{25-27}$. The chemical composition of hemicellulosic extracts obtained form $P$. radiata showed a high amount of hexoses that could be used for bioethanol through fermentation with the microorganisms traditionally used for this purpose. Pentoses can be converted into furfural, a high added-value chemical, by acid dehydration ${ }^{26}$. The incorporation of the pre-hydrolysis step of hemicelluloses from wood used by the pulp and paper industry could also provided and interesting way for the implementation of a Forest Biorefinery in a short period of time. 


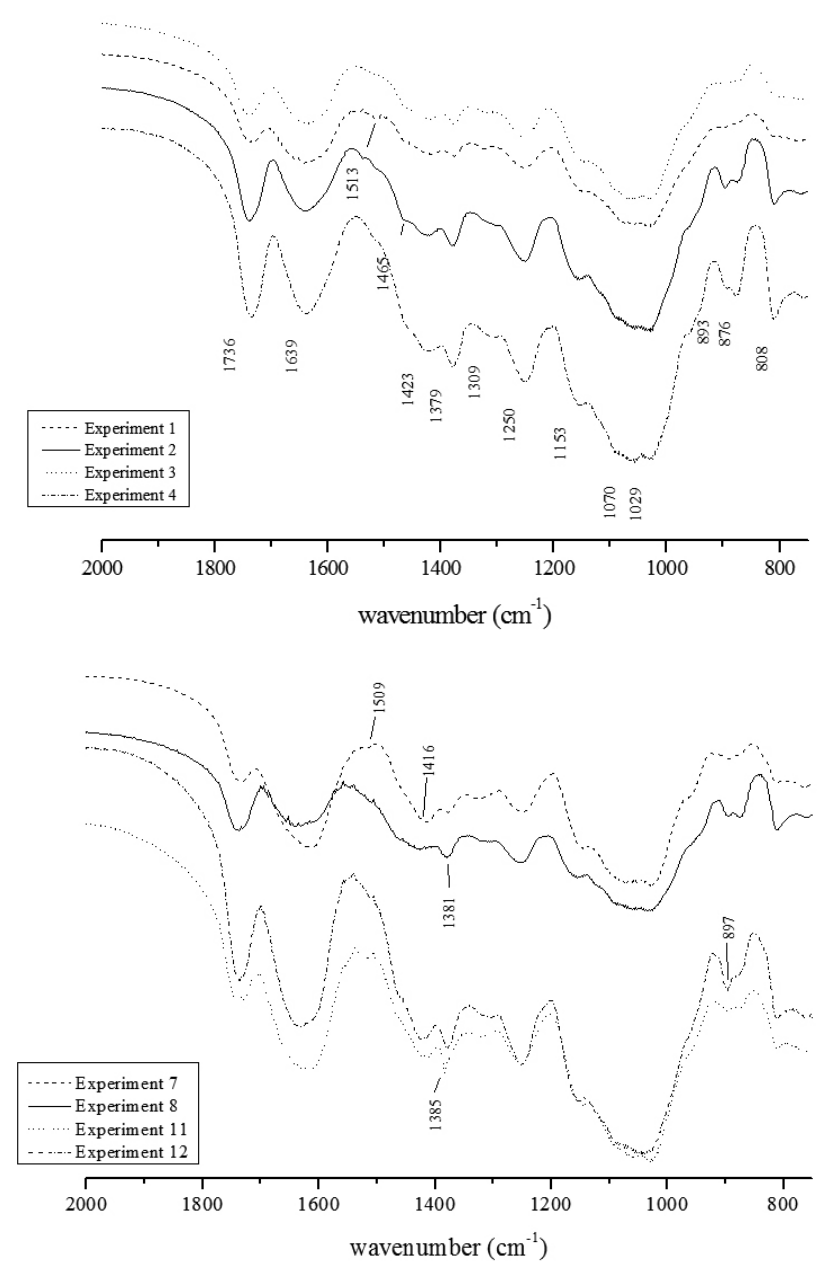

Figure 4. FT-IR spectra of hemicelluloses obtained (a) neutral extraction and (b) alkaline extraction.

\section{CONCLUSIONS}

Hot-water extraction of $P$. radiata was effective in extracting up to $58 \%$ of hemicelluloses from wood with different molar mass distribution according to the extraction conditions. Extracts were mainly enriched in hexoses from the galactoglucomannans. The extent of the solubilization of hemicelluloses was influenced by the reaction time and temperature being the initial $\mathrm{pH}$ of aqueous solution less important according to the models developed with the results of the experimental design. The characteristics of the hemicelluloses obtained make it a material useful for biofuels or bioproducts in accordance with the biorefinery concept of integral use of forest biomass.

\section{ACKNOWLEDGEMENTS}

Financial support from PBCT-Conicyt/AKA (grant CCF-07) and P. Reyes' PhD grant (Conicyt 21090162) are acknowledged. The authors thank Prof. Thomas Heinze (Centre of Excellence for Polysaccharide Research, Friedrich Schiller University of Jena, Jenna, Germany) for molar mass analysis of hemicelluloses.

\section{REFERENCES}

1. E. Sjöström, Wood Chemistry. Fundamental and applications, 2nd ed. London, UK: Academic Press Inc., 1993.

2. H. Stalbrand, J. Lundqvist, A. Andersson, P. Hagglund, L. Anderson, F. Tjerneld, A. Jacobs, A. Teleman, O. Dahlman, M. Palm, G. Zacchi, In Hemicellulose: Science and technology, P. Gatenholm, M. Tenkanen, American Chemical Society, Washington, DC, 66 (2004).

3. M. S. Tunc and A. R. P. van Heiningen, Carbohyd Polym. 83, 8 (2011).
4. R. C. Sun, J. Tomkinson, Carbohyd Polym. 50, 263 (2002).

5. J. Helmerius, J. V. von Walter, U. Rova, K. A. Berglund, D. B. Hodge, Bioresour. Technol. 101, 5996 (2010).

6. F. Peng, P. Peng, F. Xu, R.-C Sun. Biotechnol. Advances, In Press. (2012).

7. M. Monrroy, J. R. Garcia, R. T. Mendonca, J. Baeza, J. Freer. J. Chil. Chem. Soc., 57, 1113-1117 (2012).

8. A. J. Ragauskas, M. Nagy, D.H. Kim, C. A. Eckert, C. L. Liotta. Industrial Biotechnology. 2, 55 (2006).

9. W. Al-Dajani, U. Tschirner. Tappi J. 7, 3 (2008).

10. H. Mao, J.M. Genco, S.H. Yoon, A.van Heiningen, H. Pendse. J. Biobased Mater. Bioenergy. 2, 177 (2008).

11. Z. Liu, Y. Ni, P. Fatehi, A. Saeed. Biomass Bioenerg. 35, 1789 (2011).

12. A. Jun, U. W. Tschirner and Z. Tauer. Biomass Bioenerg. 37, 229 (2002).

13. S. Yoon, K. Macewan, A. Van Heiningen, Tappi J. 7, 27 (2008).

14. J.J. Paredes, R. Jara, A. van Heiningen, S.M. Shaler. Forest Prod. J. 58, 56 (2008).

15. A. van Heinigen, L. Ward, W. Astbury, D. Gardner, G. Goyal, Integrated Forest Products Refinery. University of Maine. 2010.

16. T. Song, A. Pranovich, I. Sumerskiy, B. Holmbom, Holzforschung. 62, 659 (2008).

17. L. Ban, X. S. Chai, J. Q. Guo, W. P. Ban, L. A. Lucia, J Agr Food Chem. 56, 2953 (2008).

18. R. T. Mendonça, J.F. Jara, V. González, J.P. Elissetche, J. Freer. J Ind Microbiol Biot. 35, 1323 (2008).

19. A. Sundberg, K. Sundberg, C. Lillandt, B. Holmbom, Nord Pulp Pap Res J. 11, 216 (1996).

20. H. Franco, R. T. Mendonca, P. D. Marcato, N. Duran, J. Freer and J. Baeza. J. Chil. Chem. Soc. 56, 901 (2011),

21. J. Lundqvist, A. Teleman, L. Junel, G. Zacchi, O. Dahlman, F. Tjerneld, H. Stalbrand, Carbohyd Polym. 48, 29 (2002).

22. R. C. Sun and J. Tomkinson, Carbohydrate Polymers, 50, 263 (2002).

23. M.-F. Li, S.-N. Sun, F. Xu, R.-C. Sun, Ultrason sonochem. 19, 243 (2012).

24. T. E. Amidon, C. D. Wood, A. M. Shupe, Y. Wang, M. Graves, S. J. Liu, J. Biobased Mater. Bioenergy . 2, 100 (2008).

25. B. C. Saha. In Hemicellulose bioconversion. Springer-Verlag Berlin. 279 (2003)

26. A. S. Mamman, J. M. Lee, Y. C. Kim, I. T. Hwang, N. J. Park, Y. K. Hwang, J. S. Chang, J. S. Hwang. Biofpr Journal. 2, 438 (2008).

27. F. M. Gírio, C. Fonseca, F. Carvalheiro, L. C. Duarte, S. Marques, R. Bogel-Lukasik. Bioresour. Technol. 101, 4775 (2010). 